\title{
Role of Sodium Channels in Epilepsy
}

\author{
David I. Kaplan ${ }^{1}$, Lori L. Isom², and Steven Petrou ${ }^{1,3,4}$ \\ ${ }^{1}$ The Florey Institute of Neuroscience and Mental Health, The University of Melbourne, Parkville, \\ Victoria 3052, Australia \\ ${ }^{2}$ Department of Pharmacology, The University of Michigan, Ann Arbor, Michigan 48109-0632 \\ ${ }^{3}$ The Centre for Neural Engineering, The Department of Electrical Engineering, The University \\ of Melbourne, Parkville, Victoria 3052, Australia \\ ${ }^{4}$ The Australian Research Council Centre of Excellence for Integrative Brain Function, The University \\ of Melbourne, Parkville, Victoria 3052, Australia \\ Correspondence: steven.petrou@florey.edu.au
}

\begin{abstract}
Voltage-gated sodium channels (VGSCs) are fundamentally important for the generation and coordinated transmission of action potentials throughout the nervous system. It is, therefore, unsurprising that they have been shown to play a central role in the genesis and alleviation of epilepsy. Genetic studies on patients with epilepsy have identified more than 700 mutations among the genes that encode for VGSCs attesting to their role in pathogenesis. Further, many common antiepileptic drugs act on VGSCs to suppress seizure activity. Here, we present an account of the role of VGSCs in epilepsy, both through their pathogenic dysfunction and as targets for pharmacotherapy.
\end{abstract}

\section{SUBTYPES AND STRUCTURE}

$\mathrm{V}_{\mathrm{res}}$ oltage-gated sodium channels (VGSCs) are responsible for the generation and propagation of action potentials (APs). Through transiently increasing membrane permeability to sodium ions, these specialized proteins facilitate diffusion down an electrochemical gradient, bringing the membrane toward the sodium equilibrium potential (Hille 2001). This depolarization forms the upstroke of the AP. The existence of ion-permeable channels, responsible for voltage gating of sodium ions across the membrane, was first hypothesized by Hodgkin and Huxley in 1952 (Hodgkin and Huxley 1952). In the time that followed, the existence of VGSCs has been proven beyond refute, and a broad family of channel subtypes have been identified and characterized (Payandeh et al. 2011; Catterall et al. 2012). There are nine different pore-forming $\alpha$-subunits $\left(\mathrm{Na}_{\mathrm{V}} 1.1-1.9\right.$ encoded for by the genes SCN1A-SCN5A and $S C N 8 A-S C N 11 A)$. Each $\alpha$-subunit is comprised of a single $\sim 260-\mathrm{kDa}$ protein composed of four repeat domains (I-IV), each containing six transmembrane $\alpha$-helical segments (S1-S6). The $S 4$ segment acts as a voltage sensor because of a high concentration of positively charged arginine residues that compel the segment to move through the electric field of the membrane (Catterall 1986; Guy and Seetharamulu 1986; Keller et al. 1986). Domains III and IV of the $\alpha$-subunit are connected by an intracellular loop that forms the channel inactivation gate, acting through a hinged lid mechanism (McPhee et al. 1998). Mutagenesis studies suggest that a phenylalanine

Editors: Gregory L. Holmes and Jeffrey L. Noebels

Additional Perspectives on Epilepsy: The Biology of a Spectrum Disorder available at www.perspectivesinmedicine.org

Copyright (C) 2016 Cold Spring Harbor Laboratory Press; all rights reserved; doi: 10.1101/cshperspect.a022814

Cite this article as Cold Spring Harb Perspect Med 2016;6:a022814 
D.I. Kaplan et al.

residue (F1489) on the intracellular loop binds to an inactivation gate receptor, which causes the loop to occlude the channel pore during the inactivation process (Patton et al. 1992; West et al. 1992; Kellenberger et al. 1997; Smith and Goldin 1997). The $\alpha$-subunit is often coupled to one or two non-pore-forming $\beta$-subunits. There are five different $\beta$-subunit proteins $(\beta 1, \beta 1 B, \beta 2, \beta 3$, and $\beta 4)$ encoded by four genes $(S C N 1 B-S C N 4 B ; \beta 1 B$ is a splice variant of $S C N 1 B$ ) (Brackenbury and Isom 2011). VGSC $\beta$-subunits are much smaller than $\alpha$-subunits $(30-50 \mathrm{kDa})$, each consisting of an extracellular immunoglobulin (Ig) loop, a single transmembrane domain, and a short intracellular domain. The physical interaction between the $\alpha$ - and $\beta$ subunits is not well characterized; however, evidence suggests that residues in the $\mathrm{A} / \mathrm{A}^{\prime}$ strand of the $\beta 1$-subunit Ig fold are involved in the $\alpha$-subunit interaction and residues in the $\beta 1$ carboxyl terminus are critical for association with $\mathrm{Na}_{\mathrm{V}} 1.1$ (McCormick et al. 1998; Spampanato et al. 2004b). In addition, $\beta 2$ - and $\beta 4$-subunits covalently associate with $\alpha$-subunits via extracellular disulfide bonds (Chen et al. 2012; Buffington and Rasband 2013). $\beta$-subunits modulate the kinetics and voltage dependence of the $\alpha$ subunits and have also been shown to affect the voltage-gated potassium channels, as well as participate in nonconducting roles, including cellcell and cell-matrix adhesion, directing neuronal proliferation, migration, and fasciculation, and modulating the effects of pharmacological compounds on VGSCs (Isom et al. 1992, 1995; Patton et al. 1994; Yu et al. 2003; Brackenbury and Isom 2011; Marionneau et al. 2012; Nguyen et al. 2012). Aside from the VGSCs, there is also a specialized sodium channel involved in sensing sodium levels. $\mathrm{Na}_{\mathrm{X}}$ is related to the family of VGSCs; however, it differs in its primary structure and is not voltage dependent (Hiyama et al. 2002).

\section{THE ROLE OF SODIUM CHANNELS IN THE NERVOUS SYSTEM}

Within the central nervous system (CNS), VGSCs are critically important for regulating neuronal excitability and, therefore, network ac- tivity. They are expressed ubiquitously throughout central neuron compartments with an increased density at nodes of Ranvier and axon initial segments (AIS). In myelinated neurons, the aggregation of VGSCs at the nodes of Ranvier is necessary for speeding AP propagation by saltatory conduction (Conti et al. 1976; Kaplan et al. 2001). The AIS serves as the site of AP initiation because of its reduced threshold of excitation relative to adjacent regions (Stuart et al. 1997a; Palmer and Stuart 2006). This has been attributed to the high concentration and unique properties of VGSCs at this site (Colbert and Johnston 1996; Kole et al. 2008). Immunohistochemistry studies have been instrumental in determining the distribution of different VGSCs along the AIS. One such study, using adult rat retinal ganglion cells, showed that $\mathrm{Na}_{\mathrm{V}} 1.6$ channels are densely expressed at the distal AIS, whereas $\mathrm{Na}_{\mathrm{V}} 1.1$ channels are aggregated in a spatially distinct region of the proximal AIS (Van Wart et al. 2007). Work looking at cortical pyramidal neurons in rats showed localization of $\mathrm{Na}_{\mathrm{V}} 1.6$ and $\mathrm{Na}_{\mathrm{V}} 1.2$ channels at the AIS distributed in a gradient along the length of the segment with increased $\mathrm{Na}_{\mathrm{V}} 1.6$ at the distal AIS and $\mathrm{Na}_{\mathrm{V}} 1.2$ more proximal ( $\mathrm{Hu}$ et al. 2009). This gradient has functional consequences as the $\mathrm{Na}_{\mathrm{V}} 1.6$ channels have a hyperpolarized voltage dependence of activation relative to the $\mathrm{Na}_{\mathrm{V}} 1.2$ channels (Hu et al. 2009). When depolarizing current from synaptic inputs enters the AIS, $\mathrm{Na}_{\mathrm{V}} 1.6$ channels in the distal compartment will reach their activation threshold more readily than $\mathrm{Na}_{\mathrm{V}} 1.2$ and, consequently, open to generate APs. Transmembrane current generated during these APs will then travel both down the axon and back toward the soma, depolarizing the membrane and activating the $\mathrm{Na}_{\mathrm{V}} 1.2$ channels to induce a backpropagating AP. This AP is actively propagated through the dendritic arbor by VGSCs expressed throughout the soma and dendrites (Lorincz and Nusser 2010). The backpropagating AP is important for relating neuronal output to synaptic input, which is necessary for regulating synaptic plasticity (Stuart et al. 1997b). Changes in plasticity can dramatically alter network dynamics by changing the functional topology of a net- 
work. Dendritic VGSCs have also been proposed to contribute to AP generation in the dendrites; however, it still remains unclear as to the relevance of this behavior in vivo (Magee and Johnston 1995; Golding and Spruston 1998). Taken together, these data show the complex relationship between VGSC distribution and network excitability and hint at the vulnerability of brain networks to changes in the function of these channels by mutation or drug action.

\section{EPILEPSY MUTATIONS IN SODIUM CHANNELS}

Genetic studies of patients with epilepsy have identified an extensive array of mutations predominantly among the genes that encode for the ion channels, earning epilepsy its classification as a "channelopathy." A substantial proportion of these mutations are in VGSC genes with the vast majority discovered in $S C N 1 A$, and fewer in $S C N 2 A, S C N 8 A$, and $S C N 1 B$ (Wallace et al. 1998, 2002; Mulley et al. 2005; Striano et al. 2006; Herlenius et al. 2007; Patino et al. 2009; Shi et al. 2009; Allen et al. 2013; O'Brien and Meisler 2013; Sawyer et al. 2014).

Mutations in SCN1A are occasionally associated with generalized epilepsy with febrile seizures (FSs) plus $\left(\mathrm{GEFS}^{+}\right)$and much more frequently with the severe epileptic encephalopathy (EE), Dravet syndrome (DS). GEFS ${ }^{+}$ mutations in SCN1A are mostly missense mutations, whereas, in DS, $40 \%$ are missense mutations, $40 \%$ are truncation, and the remainder are splice-variant changes (Marini et al. 2011). Although earlier work suggested that mutations in SCN2A are primarily associated with the self-limiting and relatively mild, benign familial neonatal infantile seizures (BFNIS), recent evidence implicates $S C N 2 A$ as an important EE gene (Ogiwara et al. 2009; Liao et al. 2010; Allen et al. 2013; Baasch et al. 2014; Hackenberg et al. 2014). A spate of de novo SCN8A mutations among patients with EEs have been identified (Veeramah et al. 2012; Estacion et al. 2014; Larsen et al. 2015). A recent study using highthroughput genetic screening identified 17 mutations in SCN8A among patients with EE (Larsen et al. 2015). Seizure onset occurred at around 5 months of age and all patients had impaired development. Seizure types varied with many patients developing multiple seizure types after initial seizure onset. Mutations in SCN1B have been identified in patients with DS, GEFS ${ }^{+}$, and temporal lobe epilepsy (Scheffer et al. 2007; Patino et al. 2009; Ogiwara et al. 2012). Most of the epilepsy-associated mutations discussed in this article are examples of highly penetrant dominant mutations. However, it seems increasingly apparent that, in many cases, epilepsy arises as a consequence of combinatorial effects of multiple mutations that are not individually deleterious. This point is nicely illustrated in a study by Klassen and colleagues (2011) who performed Sanger sequencing on 237 ion-channel genes in 152 patients with idiopathic epilepsy and 139 healthy controls. This study identified thousands of singlenucleotide polymorphisms (SNPs). Interestingly, these were distributed among both epilepsy patients and controls with no clear separation. Further, when the investigation was limited to genes that were known to be associated with epilepsy, the investigators found a significant number of missense mutations among the control group. These findings suggest that common genetic epilepsies are caused by an accumulation of mutant ion channels, rather than highly penetrant rare variants.

\section{FUNCTIONAL ANALYSIS OF SODIUM CHANNEL MUTATIONS: IMPLICATIONS FOR DIFFERENT SPATIAL SCALES}

Since the discovery of the first epilepsy-associated genetic mutation, an extensive body of work has focused on understanding the functional consequence of these mutations in model systems. VGSC mutations have been investigated on multiple spatial scales, from the level of single channels heterologously expressed in nonneuronal cell lines, extending to network and whole animal experiments from genetically engineered models. Each of these models offers unique insights into the functional mechanisms of mutations, which can help to build a comprehensive understanding of the mechanisms underlying genetic epilepsies. 
D.I. Kaplan et al.

\section{CHANGES IN SODIUM CHANNEL BIOPHYSICS: INSIGHTS FROM CELL CULTURES}

Mutant channels can be transfected into heterologous expression systems to interrogate changes in channel biophysics. Using quiescent cell lines, currents generated by a heterologously expressed mutant channel can be readily isolated. With this approach, a growing number of VGSC mutations identified in patients with epilepsy have been analyzed. However, these results must be interpreted with caution as a nonneuronal cell line may lack essential components that affect VGSC function and cannot fully recapitulate the internal milieu of a neuron. Moreover, differences in recording conditions, cell line type, and passage history confound comparison of results across different studies.

\section{SCN1A MUTATIONS}

Of the SCN1A mutations, more than one-half are truncation mutations, resulting in haploinsufficiency, whereas the remainder are missense mutations that have effects on the kinetics or voltage dependence of channel gating. Work looking at the effects of such missense mutations from patients with $\mathrm{GEFS}^{+}$showed variable results. Early studies using heterologous expression systems suggest mutations result in a gain of function as a result of impaired channel inactivation (Lossin et al. 2002). This idea was soon challenged by characterization of several lossof-function $\mathrm{GEFS}^{+}$mutations caused by various different biophysical modifications, such as positive shifts in the voltage dependence of activation or increased slow inactivation (Lossin et al. 2003). To date, no uniform change in $\mathrm{Na}_{\mathrm{V}} 1.1$ biophysics has been identified in GEFS ${ }^{+}$ mutations; however, given that these channels are interneuron specific, it is assumed that the disease-causing mechanism will converge at a higher spatial level (Ogiwara et al. 2007; Escayg and Goldin 2010). Under specific circumstances, VGSC gain of function could suppress neuronal excitation. In interneurons, this could lead to disinhibition as a chronically depolarized neuron would reduce channel availability and impair AP firing.

\section{SCN2A MUTATIONS}

Missense mutations in SCN2A are associated with BFNIS. Characterization of two BFNIS mutations using tsA201 cell lines has shown a depolarizing shift in the voltage dependence of inactivation and an increased persistent current causing an overall gain of function (Kearney et al. 2001; Liao et al. 2010; Lauxmann et al. 2013). This hypothesis is consistent with disease progression with onset at 11 weeks postnatal and remission within 1 year. $\mathrm{Na}_{\mathrm{V}} 1.2$ channels are expressed in two different splice forms, neonatal and adult. The adult splice form is more excitable than the neonatal; subsequently, a more excitable mutant channel could induce seizures in a neonate, but be benign in an adult. In a recent study by Gazina and colleagues (2015), a mouse was generated that only expressed the adult isoform of the $\mathrm{Na}_{\mathrm{V}} 1.2$ channel, even in infancy. These $\mathrm{Na}_{\mathrm{V}} 1.2^{\text {adult }}$ mice showed an increase in AP firing in cortical neurons and were more susceptible to seizures. In a related study by Xu and colleagues (2007b), the effects of a BFNIS mutation on the adult and neonatal splice forms of the $\mathrm{Na}_{\mathrm{V}} 1.2$ channel are compared in HEK293t cells. The mutation results in a gain of function that is more pronounced for the neonatal form of the channel than for the adult. Further, the gain of function caused by the mutation in the neonatal form increases channel excitability to a level similar to that of the adult wild-type channel. This, indeed, suggests that the functional consequence of the mutation is severely diminished in the adult offering an explanation for the self-limiting nature of the disease (Xu et al. 2007b). Biophysical characterizations of SCN2A mutations in EEs are currently lacking, and it remains to be seen what, if any, functional changes are correlated with these severe and clinically important disorders.

\section{SCN8A MUTATIONS}

De novo mutations in SCN8A have been associated with EEs resulting in a broad spectrum of different seizure types, including absence epilepsy. A de novo mutation in the SCN8A gene 
was identified in a child with EE who died from sudden unexpected death in epilepsy (SUDEP) at age 15 (Veeramah et al. 2012). The patient carried a heterozygous missense mutation, resulting in a $\mathrm{N} 1768 \mathrm{D}$ variant $\mathrm{Na}_{\mathrm{V}} 1.6$ protein. When the mutant protein was expressed in ND7/23 cells, voltage-clamp assays revealed a gain of function with an increase in persistent current, ramp current, a depolarizing shift in steady-state inactivation, and incomplete channel inactivation. Another patient showing developmental delay, intellectual disability, and intractable epilepsy was discovered to carry a heterozygous mutation c. $2300 \mathrm{C}>\mathrm{T}$ in the SCN8A gene, resulting in a T767I variant (Estacion et al. 2014). Functional analysis revealed a gain of function with a hyperpolarizing shift of $10 \mathrm{mV}$ in the voltage dependence of activation, as well as an increase in ramp current. Together, these studies would suggest gain of function as a common mechanism for SCN8A-related epilepsies; however, an additional study of a de novo missense mutation in a young girl with EE, resulting in a $\mathrm{R} 233 \mathrm{G}$ protein variant, showed a loss of function measured as a significant reduction in current amplitude (de Kovel et al. 2014). Mutations in SCN8A have also been identified in forms of epilepsy other than EE. Absence seizures have distinct 3-Hz spike-wave discharges and highfrequency bursts associated with behavioral arrest and transient impairment of cognition. Through a chemical mutagenesis screen, mutations in the mouse Scn8a gene were shown to cause absence seizures with spike-wave discharges measured through electroencephalography (EEG) (Papale et al. 2009). Voltage-clamp analysis of the mutant channels showed an overall loss of function indicated by a depolarizing shift in the voltage dependence of activation, a hyperpolarizing shift in the voltage dependence of inactivation, and accelerated entry into fast inactivation (Oliva et al. 2014). Severity of the absence phenotype varied depending on the strain of mouse used, and this was shown to be dictated by the variant of other VGSC subtypes expressed in the same neuron. A general trend that can be concluded from this work is that SCN8A gain-of-function mutations tend to result in $\mathrm{EE}$, whereas loss of function seems to induce absence seizures.

\section{SCN1B MUTATIONS}

Mutations in $S C N 1 B$, encoding the $\beta 1-/ \beta 1 B$ subunits, have been associated with a number of different forms of epilepsy. To study these proteins in heterologous expression systems, they must be coexpressed with an $\alpha$-subunit. All of the SCN1B mutations identified in epilepsy patients (except for one identified in the specific carboxy-terminal domain of $\beta 1 \mathrm{~B}$ ) ( $\mathrm{Pa}-$ tino et al. 2011) are located in the extracellular Ig fold involved in cell-cell adhesion and $\alpha$-subunit interaction. Unsurprisingly, characterization of these mutations suggests a loss of function of the $\beta$-subunit, resulting in a slowing of $\alpha$-subunit inactivation, a hyperpolarizing shift in sodium current voltage dependence of inactivation, and increased resilience to use-dependent loss of availability (Meadows et al. 2002; Tammaro et al. 2002; Xu et al. 2007a; Patino et al. 2009). It has also been shown that $\beta 1$ interacts with and modulates certain potassium channel subtypes, best illustrated in a study in which $\beta 1$ was knocked down in mice, resulting in a reduction in A-type potassium current density, an increase in AP half-width, and an increase in repetitive firing (Marionneau et al. 2012). $\mathrm{GEFS}^{+}$-related mutations of $S C N 1 B$ can interfere with $\beta 1$ modulation of potassium currents (Nguyen et al. 2012). $\beta 1$ accelerates the activation and reduces cumulative inactivation of the potassium channel $\mathrm{K}_{\mathrm{V}} 1.3$; however, these effects are lost with two $\mathrm{GEFS}^{+}$mutations of SCN1B, the C121W, and R85C mutations. A mutation in the region of the $S C N 1 B$ gene unique to the $\beta 1 \mathrm{~B}$ splice variant has been suggested to cause aberrant neuronal migration as it causes intracellular retention of the subunit, which must be secreted to act as a cell-adhesion molecule (CAM) (Patino et al. 2011). Determining the effect of these mutations on channel gating is crucially important; however, for a comprehensive picture of how VGSC mutations induce epilepsy, it is necessary to scale out to models that capture the broader aspects of seizure behavior. 
D.I. Kaplan et al.

\section{SUMMARY OF BIOPHYSICAL PATHOMECHANISMS IN EPILEPSY}

Functional analyses of epilepsy mutations in VGSCs have revealed a complex picture; however, a specific pattern relating channel mutation to epileptic syndrome has begun to emerge. Changes in channel biophysics tend to be cell-type dependent with VGSCs in interneurons, for example, $\mathrm{Na}_{\mathrm{V}} 1.1$ or $\mathrm{Na}_{\mathrm{V}} 1.6$, showing loss of function because of haploinsufficiency, depolarizing shifts in the voltage dependence of activation, and hyperpolarizing shifts in voltage dependence of inactivation. Contrastingly, changes in pyramidal cell channels, for instance, $\mathrm{Na}_{\mathrm{V}} 1.2$ or $\mathrm{Na}_{\mathrm{V}} 1.6$, tend to be gain of function, such as depolarizing shifts in the voltage dependence of inactivation and an increase in persistent current. Broadly, SCN1A haploinsufficiency tends to cause DS, as does $S C N 1 B$ loss of function. Gain of function in $S C N 2 A$ relates to BFNIS. Gain of function in $S C N 8 A$ has been associated with EE, whereas loss of function relates to absence. Additional potential pathomechanisms have been proposed, but not yet specifically identified, in patients with epilepsy. Mutations in the VGSC voltage sensor, which substitute the charged arginines with neutral residues, can result in a leak current through the voltage sensor, referred to as the "omega" or "gating pore" current (Sokolov et al. 2005). Although this has not yet been reported in patients with epilepsy, a mutation in $\mathrm{Na}_{\mathrm{V}} 1.4$ associated with hypokalaemic periodic paralysis has been shown to have an increased omega current, implicating this mechanism among channelopathies (Sokolov et al. 2007). One other gating phenomenon that has been proposed as a pathomechanism of epilepsy is resurgent sodium current. For certain subtypes of VGSCs, a small transient inward current can be elicited with repolarization of the membrane following a prolonged depolarizing pulse ( $\mathrm{Ra}$ man and Bean 1997). Increased resurgent current amplitude has been associated with an increase in AP firing frequency, implicating it as a potential pathomechanism in epilepsy (Martin et al. 2007; Jarecki et al. 2010; Hargus et al. 2013).

\section{STEM-CELL MODELS}

A common criticism of the use of heterologous expression systems to explore mutant channel biophysics is the lack of neuronal context, which may mask pathologically important functional changes. With recent developments in stemcell- and genome-editing technologies, this limitation can be potentially overcome. In a study by Liu and colleagues (2013), fibroblasts obtained from skin biopsies of patients with DS were used to generate induced pluripotent stem cells (iPSCs), which were then differentiated into forebrain neurons with bipolar and pyramidal morphologies. Electrophysiological assays revealed a marked increase in neuronal excitability in DS-patient-derived excitatory and inhibitory neurons relative to nonepileptic patient control iPSC-derived neurons. Voltageclamp recordings showed a twofold increase in sodium current density at 3-5 weeks in DS neurons relative to controls, and current clamp experiments showed a reduced threshold of AP generation, increased evoked firing frequency, and spontaneous firing in excitatory and inhibitory DS patient neurons. The observation of similar effects in both pyramidal and bipolar neurons suggested an overall increase in neuronal excitability caused by the mutations. In a related study, glutamatergic neurons were derived from iPSCs from a patient with DS, a patient with FS, and a healthy control (Jiao et al. 2013). In both the DS and FS patients' cell lines, spontaneous APs were recorded, and voltageclamp analysis showed an increase in sodium current amplitude and incomplete inactivation. These effects were more pronounced in the DS cell line, and treatment with phenytoin appeared to reverse them. Using patient-derived iPSCs preserves the genetic background that contributes to the epilepsy phenotype. Consequently, in spite of similar changes observed in two different DS patients in the Liu et al. (2013) study, differences between the control and patient-derived cells could be caused by a variety of background genetic differences. To constrain the number of variables, new methods using targeted genome editing in stem cells are being developed. A number of single-nucleotide ge- 
nome-editing methods are now available, including clustered regularly interspersed palindromic repeats (CRISPRs), which can be used to introduce a known epilepsy mutation into iPSCs derived from a healthy control or to repair mutations in patient-derived stem cells (Cong et al. 2013). Comparing the behavior of these cells with control iPSCs from the same patient will reveal the effect of the specific mutation on neuronal biophysics independent of the genetic background. Efforts are underway to extend the iPSC method to generate human brain-like structures to examine synapse formation and function, as well as network properties, allowing for the more detailed and physiologically relevant investigation of epilepsy mechanisms (Lancaster et al. 2013).

\section{SCALING OUT: EPILEPSY AS A NETWORK PHENOMENON}

\section{Animal Models of Sodium Channel Mutations}

Understanding how mutations affect channel biophysics is crucial to disentangling a complex disease such as epilepsy. As a network scale disorder, it is important to analyze the impact of mutant VGSCs in this context. This is best achieved through the generation of genetically modified animal models harboring epilepsy mutations identified in patients. In one such study, a knockin mouse line was generated with a nonsense mutation R1407X of the SCN1A gene that had been independently identified in four patients with DS (Ogiwara et al. 2007). When mice were homozygous for the mutation, they generated spontaneous seizures and died prematurely. Immunohistochemistry suggested that the $\mathrm{Na}_{\mathrm{V}} 1.1$ channels were localized to the AIS of parvalbumin-positive inhibitory interneurons. Patch-clamp recording of these neurons in the $S c n 1 a^{R X /+}$ mice showed no change in AP threshold, amplitude or halfwidth; however, the decrement in spike amplitude was significantly increased in the mutant mice. This speaks to a reduction in sodiumchannel availability in these neurons, reducing their excitability and, consequently, reducing global inhibition in the mouse brain. This work supports the hypothesis that SCN1Abased DS results from an imbalance of the excitation:inhibition $(\mathrm{E} / \mathrm{I})$ ratio caused by the selective loss of VGSCs in inhibitory neurons (Fig. 1) (Yu et al. 2006; Ogiwara et al. 2007). To explore mechanisms in $\mathrm{GEFS}^{+}$, a missense SCN1A mutation, $R 1648 \mathrm{H}$, identified in $\mathrm{GEFS}^{+}$patients, was knocked into mice with mixed genetic backgrounds, and electrophysiological assays were used to compare the biophysical properties of inhibitory and excitatory neurons in this model (Martin et al. 2010). Voltage-clamp analysis showed that in wild-type animals sodium current density was substantially greater in inhibitory bipolar cells than in excitatory pyramidal neurons with a ratio of 2.7 , whereas in the $S_{c n} 1 a^{R H / R H}$ and $S c n 1 a^{R H /+}$ mice, this ratio was closer to one as a result of a reduced sodium current in bipolar cells. Consistent with this result, bipolar cells in $S c n 1 a^{R H / R H}$ mice showed significantly reduced excitability compared with those in the wild-type mice. This result suggests that $\mathrm{GEFS}^{+}$may share a similar imbalance of E/I as in DS, albeit with differences that account for the different clinical presentations. Beyond SCN1A, mutations in other VGSC genes have also been investigated using rodent models. In a recent study, a de novo missense mutation in SCN8A that had been identified in a patient with EE and SUDEP was knocked into a mouse line and shown to be sufficient to recapitulate the epileptic phenotype (Wagnon et al. 2015). This gain-of-function mutation resulted in increased persistent current in transfected neurons and was proposed to account for neuronal hyperexcitability in the mice. Mice that were heterozygous for the mutation showed no symptoms for the first 2-3 months of age, at which point seizure onset ensued and death occurred within a month. Generalized tonic-clonic seizures were observed that would last no more than 1 minute and were accompanied by distinct EEG signatures. Taken together, these studies show the power of animal models of genetic epilepsies for exploring pathogenesis.

Using mice to understand the implications of epilepsy mutations has obvious benefits; they are mammalian, their genome has been thoroughly analyzed, and a wealth of tools and pro- 
D.I. Kaplan et al.

A

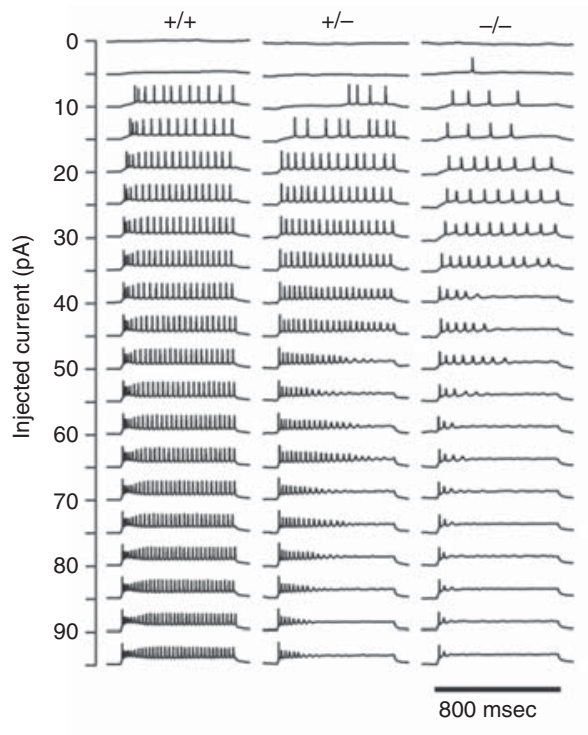

B

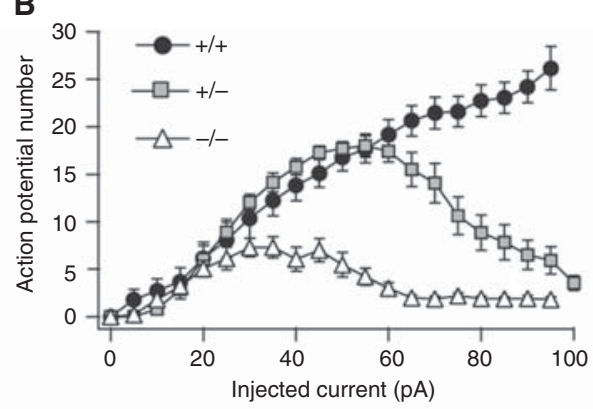

C

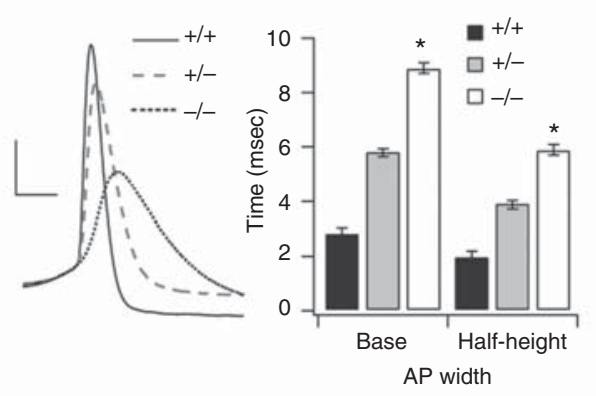

D

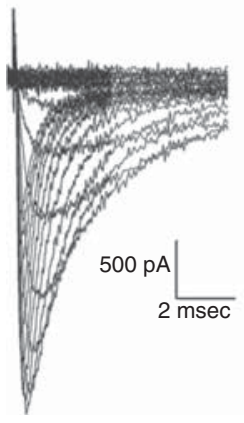

E

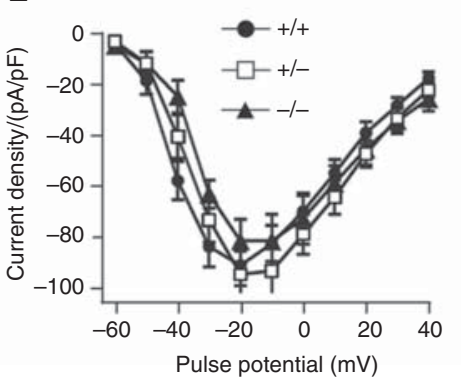

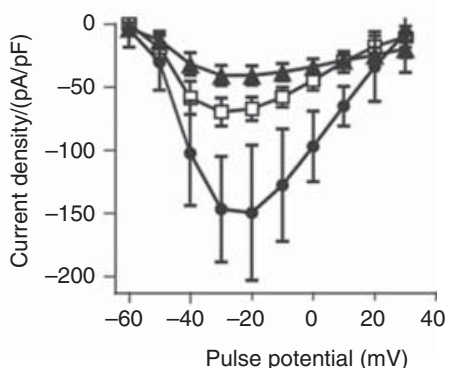

Figure 1. Scn1a knockout and heterozygous mice show a reduction of sodium currents localized to inhibitory interneurons (Yu et al. 2006). (A) Sample voltage traces from current clamp recordings of mouse $\gamma$-aminobutyric acid (GABA)ergic interneurons in the wild-type (WT) (left), heterozygous (middle), and null (right) Scnla mice, showing a marked reduction in cell excitability in the heterozygous and null mice, summarized in $B$. $(C)$ The size of action potentials (APs) was also reduced with the mutation, whereas the width of APs increased. $(D)$ Voltage-clamp recordings of isolated sodium currents. (E) I-V curves showing that the mutation does not affect current density in pyramidal neurons (left), whereas it does cause a reduction in current in GABAergic neurons (right) (figure created from data in Yu et al. 2003, 2006).

tocols are available. However, there are additional animal models that can often be more appropriate to answer certain questions about genetic epilepsies. Zebrafish have become a popular animal model in the neurosciences and, more recently, within epilepsy research (Hortopan et al. 2010). A line of zebrafish carrying a mutation in the scn 1 Lab gene (the zebrafish gene most equivalent to human $S C N 1 A$ ) have been shown to recapitulate the epilepsy phenotype both in terms of behavior and electrographic activity (Baraban et al. 2013). Using these fish, a semiautomated high-throughput drug screen was developed to identify effective antiepileptic drugs (AEDs). Drosophila melanogaster has also been used as an epilepsy model and has the advantage that it can breed rapidly and has long served as a tool for genetic studies, with a host of 
methods for genome editing. It has recently been used to investigate a number of epilepsy mutations in SCN1A (Sun et al. 2012; Schutte et al. 2014). In one such study, a GEFS ${ }^{+}$mutation, K1270T, was knocked into the para VGSC gene of Drosophila (Sun et al. 2012). These flies developed thermogenic seizures and electrophysiological analysis revealed temperature-dependent changes in VGSC biophysics, implicating a possible mechanism. Despite the simplicity of working with these nonmammalian animal models, using species so phylogenetically distant from humans introduces distinct obstacles for translation into clinical outcomes.

\section{Downstream Effects on Cellular Physiology}

VGSC mutations can lead to a host of downstream effects that may not be intuitively apparent from electrophysiological analysis, highlighting the value of using genetically modified animal models to understand the pathomechanisms of VGSC mutations. Mutations in $S C N 1 B$ have been identified in patients with $\mathrm{GEFS}^{+} . \beta 1$ subunits, encoded by $S C N 1 B$, are both VGSC modulators and CAMs necessary for neurite growth, cell migration, and normal cell morphology (Brackenbury and Isom 2011).

The generation of an $S c n 1 b$ null mouse line, $S c n 1 b^{-/-}$, has offered great insight into the role of this protein and its involvement in epilepsy (Chen et al. 2004). Scn1 $b^{-/-}$mice appear ataxic and show spontaneous seizures, lasting from seconds to minutes, which have been correlated with high-voltage, synchronous discharges on the EEG (Chen et al. 2004). Further characterization of this mouse line has shown significant cytoarchitectural defects, including a reduction in the number of nodes of Ranvier in neurons of the optic nerve, aberrant pathfinding in the corticospinal tract and cerebellum, reduced density of neurons in the dentate gyrus, and increased cell proliferation in the hilus (Chen et al. 2004; Brackenbury et al. 2013). Importantly, pathfinding differences occur in $S c n 1 b$ null brain before seizure onset, suggesting that hyperexcitability may result from these defects. This work offers a broad picture of the importance of the $\beta 1$-subunit, and shows how its absence leads to an epileptic phenotype, consistent with the finding that inheritance of two mutant $S C N 1 B$ alleles in human patients results in DS (Patino et al. 2009; Ogiwara et al. 2012). In light of this, it is not surprising that a specific $S C N 1 B$ mutation identified in humans with epilepsy could induce epilepsy in a mouse. Mice carrying the GEFS $^{+}$ missense mutation $\beta 1-\mathrm{C} 121 \mathrm{~W}$ have been well characterized, revealing a host of downstream effects. These mice show a FS phenotype in which seizures are induced by an increase in core temperature with a reduced threshold relative to wild-type littermates (Fig. 2) (Wimmer et al. 2010). Electrophysiological analysis of subicular pyramidal neurons showed an increase in excitability in heterozygous CW mice relative to wild-type CC littermates. In response to $400 \mathrm{msec}$ suprathreshold current injections, cells fired initial bursts followed by tonic AP firing. In the CW mice, bursts were more protracted and tonic-firing frequency was increased. Further, the threshold for AP initiation was, on average, $2.7 \mathrm{mV}$ more hyperpolarized in CW mice relative to CC mice. Using fluorescent labeling of $\beta 1$-subunits in combination with immunofluorescent staining against the AIS protein ankyrin-G, they showed that the native $\beta 1(\mathrm{C} 121)$ protein is aggregated at the AIS, whereas the $\beta 1(\mathrm{~W} 121)$ mutant is excluded from this compartment. Changes in VGSC functioning at the AIS can have significant implications for neuronal excitability, as this is the site of AP initiation. Scaling out even further, changes in neuronal excitability can have unpredictable effects on network behavior. This notion is explored in a related study in which the same mouse line was used to investigate network properties of the C121W mutation (Fig. 2) (Hatch et al. 2014). Tetanic stimulation of the CA1 in a slice preparation resulted in a brief oscillation as recorded by an extracellular recording electrode. In CW mice, the duration of oscillations was extended and the latency to oscillation following the stimulus was reduced. This effect was also shown to be exacerbated with increased bath temperature. These studies begin to paint a picture of the elaborate consequences of small changes in channel structure. 
D.I. Kaplan et al.

A

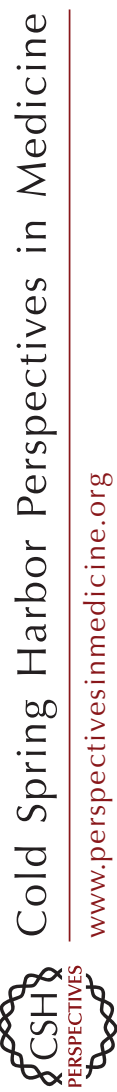

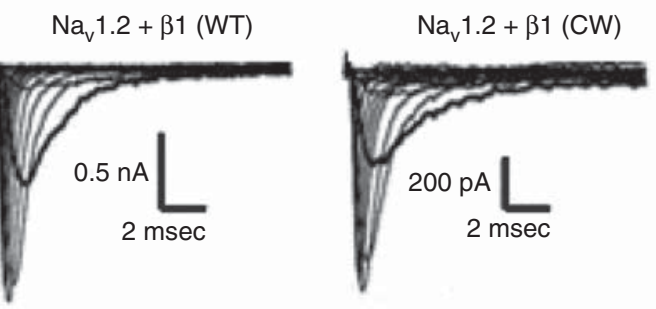

C

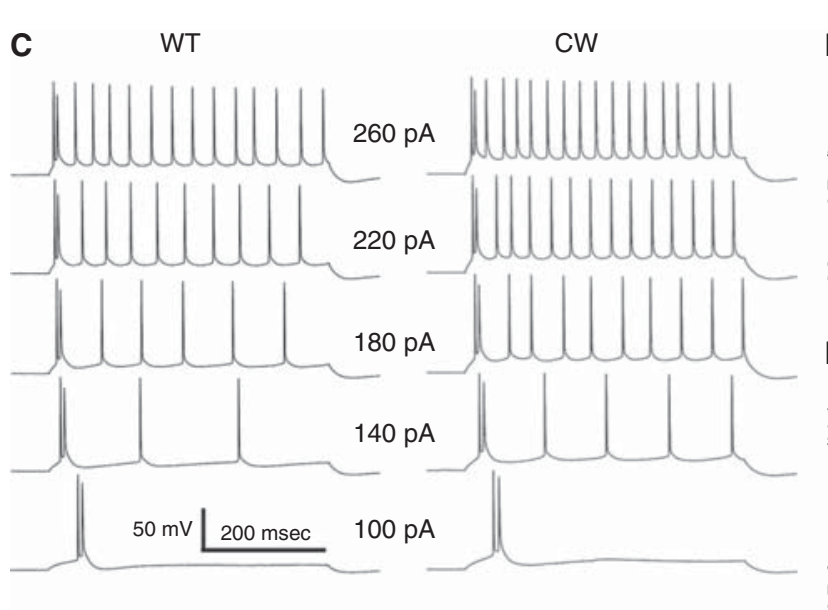

B

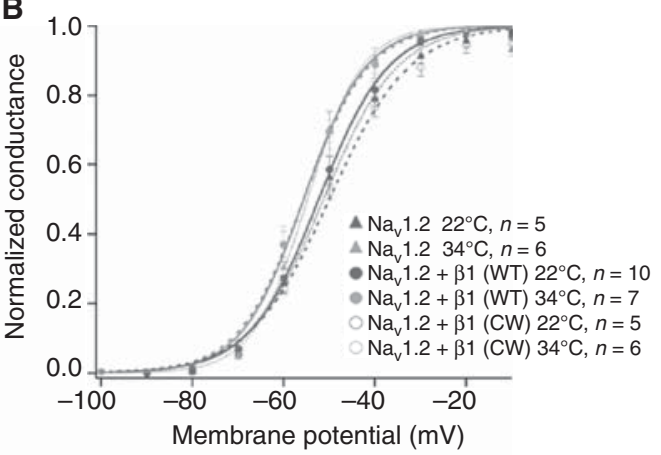

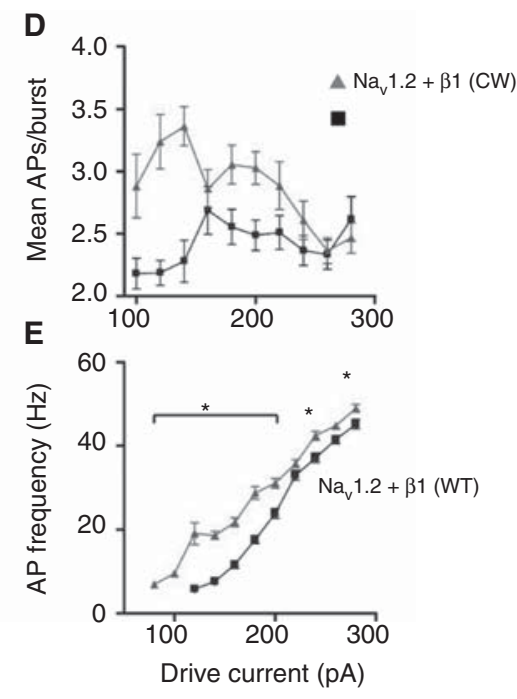
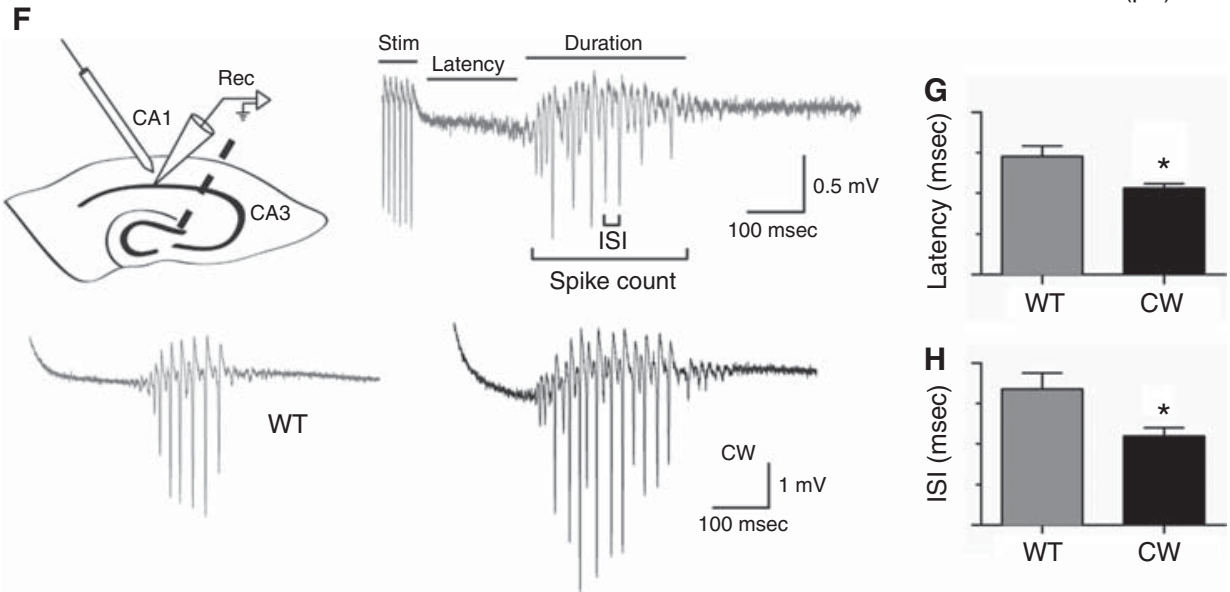

Figure 2. The functional consequences of channel mutations can be analyzed on different spatial scales (Wimmer et al. 2010; Egri et al. 2012; Hatch et al. 2014). (A) Current traces from voltage-clamp analysis of $\mathrm{Na}_{\mathrm{v}} 1.2 \mathrm{VGSC}$ $\alpha$-subunits coexpressed with either the wild-type (WT) $\beta 1$-subunit (left) or the $\mathrm{GEFS}^{+}$mutation C121W (right) in Chinese hamster ovary $(\mathrm{CHO})$ cells. $(B)$ Voltage dependence of activation for the $\mathrm{Na}_{\mathrm{V}} 1.2, \mathrm{Na}_{\mathrm{V}} 1.2+\beta 1$ (WT), and $\mathrm{Na}_{\mathrm{V}} 1.2+\beta 1(\mathrm{CW})$ at $22^{\circ} \mathrm{C}$ and $34^{\circ} \mathrm{C}$. (Legend continues on following page.) 


\section{BRIDGING THEORY AND EXPERIMENT: COMPUTATIONAL MODELING OF SODIUM CHANNEL MUTATIONS}

\section{Computational Models Can Reveal \\ a Pathological Mechanism}

Changes in channel biophysics induced by mutations can be quantified through voltageclamp analysis. Through the use of animal models, the effects of channel mutations on both neuronal and network excitability can be measured. A challenge arises when trying to causally relate these changes, measured on different spatial scales. Computational modeling of neuronal biophysics has emerged as a useful means of overcoming this challenge. Biophysical properties of channels, neurons, and networks can be measured through common electrophysiological techniques. These properties can then be described mathematically and simulated on a computer (Hodgkin and Huxley 1952; Lytton 2008). A prime example of computational modeling is shown in a previously discussed study looking at the $\mathrm{C} 121 \mathrm{~W}$ heterozygous mouse (Wimmer et al. 2010). The AIS is a small compartment, notoriously difficult to access with a patch-clamp electrode. To circumvent this limitation, the investigators produced a biophysically realistic computational model of a pyramidal neuron using NEURON simulation software, and systematically altered the behavior of AIS VGSCs in an attempt to recreate the effects of the mutation on AP dynamics measured at the soma (Hines and Carnevale 1997). Negatively shifting the voltage dependence of activation for VGSCs in the AIS, they were able to mirror the increase in excitability measured in the CW mouse. This illustrates the importance of AIS VGSCs to neuronal and network excit- ability and offers an explanation of how loss of $\beta 1$ modulation at the AIS could result in aberrant AP firing. Computational models can also be used to investigate the implications to neuronal activity of different changes in channel biophysics induced by epilepsy mutations. Spampanato and colleagues (2001, 2003, 2004a) used previously quantified changes in $\mathrm{Na}_{\mathrm{V}} 1.1$ biophysics caused by three different $\mathrm{GEFS}^{+}$mutations to generate a NEURON simulation of the somatic compartment to explore the consequences on AP firing. Despite having distinct effects on channel biophysics, all three mutations converged at the scale of the neuron and resulted in an increase in AP firing, indicating how different mutations can lead to a single convergent pathology. Modeling can also be used to predict the effects of mutations at the network scale. In one study, a physiologically realistic model of the dentate gyrus was used to study the effects of functional changes in different ion channels (Santhakumar et al. 2005). Previous studies had shown that the most common changes in channel biophysics caused by epilepsy mutations were small shifts in the voltage dependence of activation and inactivation. In one such study, these properties were systematically varied in all voltage-dependent channels both independently and in combination with one another. Network excitability was most sensitive to changes in VGSC activation with even small hyperpolarizing shifts having a profound effect. Again, this study presents the power of VGSCs in regulating network excitability, and the potential for pathological behavior when they malfunction. Conversely, it alludes to the potential of exploiting VGSCs to reestablish physiological network activity (Thomas et al. 2009).

Figure 2. (Continued) Increasing temperature results in a shift of the voltage of half activation, which is most significant in the $\mathrm{Na}_{\mathrm{V}} 1.2+\beta 1(\mathrm{CW})$. (C) Current clamp recordings showing the voltage response of mouse subicular neurons to current injections in WT (left) and C121W heterozygous (right) mice. $(D)$ For most current injections, the $\mathrm{C} 121 \mathrm{~W}$ mouse showed an increase in action potentials (APs) frequency $(E)$ and the average number of APs per burst. $(F)$ Through tetanic stimulation, network oscillations could be induced in the mouse hippocampus. $(G)$ The latency and $(H)$ interspike interval of these oscillations was reduced in the $\mathrm{C} 121 \mathrm{~W}$ mouse (figure created from data in Wimmer et al. 2010, Egri et al. 2012, and Hatch et al. 2014). ISI, Interspike interval. 
D.I. Kaplan et al.

\section{SODIUM CHANNELS AS A TARGET FOR AEDs}

\section{The Modulated Receptor Model}

Given the central role of VGSCs in regulating neuronal excitability, it is intuitively satisfying that many common AEDs exert their action on the CNS by targeting VGSC function. The principal mode of action of these AEDs appears to be use-dependent block, in which inhibition of sodium currents is stronger when the membrane potential experiences repeated excursions to depolarized levels more frequently, exposing new drug-binding sites and allowing for selective block of channels only when they are in active neurons (Adler et al. 1986; McLean and Macdonald 1986; Ragsdale et al. 1991). Such activity occurs during seizures, in which neurons fire bursts of high-frequency APs, and AEDs may prevent seizures by impeding these high-frequency bursts through gradual inhibition of VGSCs (McNamara 1994). This manner of drug-channel interaction has been described by the modulated receptor hypothesis, which posits that for channels that transition through multiple states, a drug will bind to the channel with varying affinities depending on the state (Hondeghem 1987). Modulated receptor behavior is characterized through voltage-clamp assays in which complex protocols are designed to tease apart the precise kinetics of drug - channel interaction. In a seminal study by Kuo and Bean (1994), the investigators showed that the AED phenytoin binds preferentially to VGSCs in the fast inactivated state, but with a slow binding rate. Using acutely dissected rat hippocampal neurons, they first showed that the degree of sodium current inhibition by phenytoin is greater at depolarized potentials. This suggests that the drug binds the channel in the inactivated state, as this is the state most significantly occupied when the membrane is depolarized. As previously mentioned, VGSC inactivation is usually described as having fast and slow components. The fast component occurs within 5-10 msec, whereas the slow component can take hundreds of milliseconds to initiate. Given the delayed onset of phenytoin block, it would seem that the drug binds pref- erentially to the slow inactivated state; however, Kuo and Bean show that the drug, in fact, binds to the fast inactivated state, but with slow kinetics, so that the binding appears to be linked to slow inactivation. To do this, they held the membrane at voltages at which fast inactivation is almost complete but there is very little slow inactivation, and showed that phenytoin exposure still slows recovery from inactivation. This implied that phenytoin is acting on the channel despite minimal slow inactivation. Further studies have shown that other related AEDs act on VGSCs with similar kinetics (Kuo and Bean 1994; Yang and Kuo 2002).

\section{Mechanisms Beyond Use-Dependent Block}

Use-dependent block of VGSCs is clearly an effective way to control seizures; however, evidence from the clinic suggests that some forms of epilepsy are not responsive to these drugs and can even be exacerbated by them (Snead and Hosey 1985; Genton et al. 2000; Thomas and Petrou 2013). In some of these cases, the most effective drugs have broad pharmacological effects including, but not exclusively, modulation of VGSC biophysics. Riluzole is currently used for the treatment of amyotrophic lateral sclerosis; however, it was originally developed as an AED. It has been shown to induce a hyperpolarizing shift in the voltage dependence of inactivation in tetrodotoxin (TTX)-sensitive VGSCs, as well as reduce resurgent sodium current and partially block P/Q-type calcium channels in presynaptic terminals reducing glutamate release (Song et al. 1997; Wang et al. 2004; Theile and Cummins 2011). In addition, an indirect mechanism involving the inactivation of a pertussis-sensitive guanosine triphosphate (GTP)binding protein has been implicated (Doble 1996; Song et al. 1997; Wang et al. 2004). The AED lacosamide (LCM) is used to treat partial seizures and has been shown to enhance VGSC slow inactivation (Errington et al. 2008). Electrophysiological studies have shown that LCM enhances slow inactivation; however, evidence suggests this is not its only mechanism of action. Radioligand-binding studies and molecular dynamics simulations have implicated the protein 
CRMP-2, which plays a role in axonal sprouting, suggesting a plasticity-related effect, however, this is disputed (Wang et al. 2010; Wolff et al. 2012). Blocking VGSCs during hyperexcitation appears to be a logical means of suppressing seizures, yet, as discussed earlier, some epilepsies are thought to result from specific loss of VGSCs in inhibitory neurons, causing an imbalance of E/I. Under these circumstances, a VGSC activator could conceivably rescue the loss of channel function in inhibitory neurons. Compounds that selectively activate $\mathrm{Na}_{\mathrm{V}} 1.1$ are novel candidates for achieving this targeted activation (Jensen et al. 2014). Given their predominant expression among inhibitory interneurons, activation of $\mathrm{Na}_{\mathrm{V}} 1.1$ is postulated to increase global inhibition and potentially prevent seizures. In genetic disorders of SCN1A, such as DS, these selective openers would specifically target any cell in which SCN1A expressed and, presumably, would restore function at the neuronal level to provide a whole brain therapeutic effect. Further research into this method is needed, yet promising results are beginning to emerge.

\section{CONCLUSION}

VGSCs are fundamentally important for the generation and propagation of APs and play a pivotal role in the regulation of network excitability. To date, the vast majority of identified epilepsy-associated mutations lie in the genes that encode VGSCs. There have been extensive efforts to understand the functional consequences of these mutations using a range of experimental models on varying spatial and temporal scales. Analysis of changes in VGSCs' biophysics using heterologous expression systems have been instrumental in characterizing mutant channels, offering some insight into the relationship between channel mutations and epileptic phenotypes. The development of animal models has helped to facilitate this process by exposing some of the higher organizational scale consequences of channel mutations. Some common epilepsies may be attributable to the combined effects of multiple mutations that cannot be readily modeled in heterologous expression studies and would, thus, rely on a combination of biological and computational models for investigation of pathomechanisms. Despite this complexity, the efficacy of AEDs that target VGSCs emphasizes their disproportionate control over the electrical stability of the brain. Epilepsy is a spectrum of disorders in which many factors converge to induce a complex phenotype. Changes in VGSC biophysics contribute to the factors that determine seizure susceptibility as they are exquisitely sensitive sites for determining neuronal excitability.

\section{REFERENCES}

Adler EM, Yaari Y, David G, Selzer ME. 1986. Frequencydependent action of phenytoin on lamprey spinal axons. Brain Res 362: 271-280.

Allen AS, Berkovic SF, Cossette P, Delanty N, Dlugos D, Eichler EE, Epstein MP, Glauser T, Goldstein DB, Han Y, et al. 2013. De novo mutations in epileptic encephalopathies. Nature 501: 217-221.

Baasch AL, Huning I, Gilissen C, Klepper J, Veltman JA, Gillessen-Kaesbach G, Hoischen A, Lohmann K. 2014 Exome sequencing identifies a de novo SCN2A mutation in a patient with intractable seizures, severe intellectual disability, optic atrophy, muscular hypotonia, and brain abnormalities. Epilepsia 55: e25-e29.

Baraban SC, Dinday MT, Hortopan GA. 2013. Drug screening in Scnla zebrafish mutant identifies clemizole as a potential Dravet syndrome treatment. Nat Commun 4: 2410 .

Brackenbury WJ, Isom LL. 2011. Na channel $\beta$ subunits: Overachievers of the ion channel family. Front Pharmacol 2: 53 .

Brackenbury WJ, Yuan Y, O’Malley HA, Parent JM, Isom LL. 2013. Abnormal neuronal patterning occurs during early postnatal brain development of Scnlb-null mice and precedes hyperexcitability. Proc Natl Acad Sci 110: 10891094.

Buffington SA, Rasband MN. 2013. $\mathrm{Na}^{+}$channel-dependent recruitment of $\mathrm{Na}_{\mathrm{v}} \beta 4$ to axon initial segments and nodes of Ranvier. J Neurosci 33: 6191-6202.

Catterall WA. 1986. Molecular properties of voltage-sensitive sodium channels. Annu Rev Biochem 55: 953-985.

Catterall WA, Raman IM, Robinson HP, Sejnowski TJ, Paulsen O. 2012. The Hodgkin-Huxley heritage: From channels to circuits. J Neurosci 32: 14064-14073.

Chen C, Westenbroek RE, Xu X, Edwards CA, Sorenson DR, Chen Y, McEwen DP, O’Malley HA, Bharucha V, Meadows LS, et al. 2004. Mice lacking sodium channel $\beta 1$ subunits display defects in neuronal excitability, sodium channel expression, and nodal architecture. J Neurosci 24: $4030-4042$.

Chen C, Calhoun JD, Zhang Y, Lopez-Santiago L, Zhou N, Davis TH, Salzer JL, Isom LL. 2012. Identification of the cysteine residue responsible for disulfide linkage of $\mathrm{Na}^{+}$ 
D.I. Kaplan et al.

channel $\alpha$ and $\beta 2$ subunits. J Biol Chem 287: 39061 39069.

Colbert CM, Johnston D. 1996. Axonal action-potential initiation and $\mathrm{Na}^{+}$channel densities in the soma and axon initial segment of subicular pyramidal neurons. J Neurosci 16: 6676-6686.

Cong L, Ran FA, Cox D, Lin S, Barretto R, Habib N, Hsu PD, Wu X, Jiang W, Marraffini LA, et al. 2013. Multiplex genome engineering using CRISPR/Cas systems. Science 339: $819-823$

Conti F, Hille B, Neumcke B, Nonner W, Stampfli R. 1976. Measurement of the conductance of the sodium channel from current fluctuations at the node of Ranvier. J Physiol 262: 699-727.

de Kovel CG, Meisler MH, Brilstra EH, van Berkestijn FM, van 't Slot R, van Lieshout S, Nijman IJ, O'Brien JE, Hammer MF, Estacion M, et al. 2014. Characterization of a de novo SCN8A mutation in a patient with epileptic encephalopathy. Epilepsy Res 108: 1511-1518.

Doble A. 1996. The pharmacology and mechanism of action of riluzole. Neurology 47: S233-S241.

Egri C, Vilin YY, Ruben PC. 2012. A thermoprotective role of the sodium channel $\beta 1$ subunit is lost with the $\beta 1$ (C121W) mutation. Epilepsia 53: 494-505.

Errington AC, Stohr T, Heers C, Lees G. 2008. The investigational anticonvulsant lacosamide selectively enhances slow inactivation of voltage-gated sodium channels. Mol Pharmacol 73: 157-169.

Escayg A, Goldin AL. 2010. Sodium channel SCN1A and epilepsy: Mutations and mechanisms. Epilepsia 51: 1650-1658.

Estacion M, O'Brien JE, Conravey A, Hammer MF, Waxman SG, Dib-Hajj SD, Meisler MH. 2014. A novel de novo mutation of SCN8A (Nav1.6) with enhanced channel activation in a child with epileptic encephalopathy. $\mathrm{Neu}$ robiol Dis 69: 117-123.

Gazina EV, Leaw BT, Richards KL, Wimmer VC, Kim TH, Aumann TD, Featherby TJ, Churilov L, Hammond VE, Reid CA, et al. 2015. "Neonatal" $\mathrm{Na}_{\mathrm{V}} 1.2$ reduces neuronal excitability and affects seizure susceptibility and behaviour. Hum Mol Genet 24: 1457-1468.

Genton P, Gelisse P, Thomas P, Dravet C. 2000. Do carbamazepine and phenytoin aggravate juvenile myoclonic epilepsy? Neurology 55: 1106-1109.

Golding NL, Spruston N. 1998. Dendritic sodium spikes are variable triggers of axonal action potentials in hippocampal CA1 pyramidal neurons. Neuron 21: 1189-1200.

Guy HR, Seetharamulu P. 1986. Molecular model of the action potential sodium channel. Proc Natl Acad Sci 83: 508-512.

Hackenberg A, Baumer A, Sticht H, Schmitt B, Kroell-Seger J, Wille D, Joset P, Papuc S, Rauch A, Plecko B. 2014 Infantile epileptic encephalopathy, transient choreoathetotic movements, and hypersomnia due to a de novo missense mutation in the SCN2A gene. Neuropediatrics 45: $261-264$.

Hargus NJ, Nigam A, Bertram EH III, Patel MK. 2013. Evidence for a role of $\mathrm{Na}_{\mathrm{V}} 1.6$ in facilitating increases in neuronal hyperexcitability during epileptogenesis. J Neurophysiol 110: 1144-1157.
Hatch RJ, Reid CA, Petrou S. 2014. Enhanced in vitro CA1 network activity in a sodium channel $\beta 1(\mathrm{C} 121 \mathrm{~W})$ subunit model of genetic epilepsy. Epilepsia 55: 601-608.

Herlenius E, Heron SE, Grinton BE, Keay D, Scheffer IE, Mulley JC, Berkovic SF. 2007. SCN2A mutations and benign familial neonatal-infantile seizures: The phenotypic spectrum. Epilepsia 48: 1138-1142.

Hille B. 2001. Ion channels of excitable membranes. Sinauer, Sunderland, MA.

Hines ML, Carnevale NT. 1997. The NEURON simulation environment. Neural Comput 9: 1179-1209.

Hiyama TY, Watanabe E, Ono K, Inenaga K, Tamkun MM, Yoshida S, Noda M. 2002. $\mathrm{Na}_{\mathrm{x}}$ channel involved in CNS sodium-level sensing. Nat Neurosci 5: 511-512.

Hodgkin AL, Huxley AF. 1952. A quantitative description of membrane current and its application to conduction and excitation in nerve. J Physiol 117: 500-544.

Hondeghem LM. 1987. Antiarrhythmic agents: Modulated receptor applications. Circulation 75: 514-520.

Hortopan GA, Dinday MT, Baraban SC. 2010. Zebrafish as a model for studying genetic aspects of epilepsy. Dis Model Mech 3: 144-148.

Hu W, Tian C, Li T, Yang M, Hou H, Shu Y. 2009. Distinct contributions of $\mathrm{Na}_{\mathrm{v}} 1.6$ and $\mathrm{Na}_{\mathrm{v}} 1.2$ in action potential initiation and backpropagation. Nat Neurosci 12: 9961002.

Isom LL, De Jongh KS, Patton DE, Reber BF, Offord J, Charbonneau H, Walsh K, Goldin AL, Catterall WA. 1992. Primary structure and functional expression of the $\beta 1$ subunit of the rat brain sodium channel. Science 256: $839-842$.

Isom LL, Ragsdale DS, De Jongh KS, Westenbroek RE, Reber BF, Scheuer T, Catterall WA. 1995. Structure and function of the $\beta 2$ subunit of brain sodium channels, a transmembrane glycoprotein with a CAM motif. Cell 83: 433-442.

Jarecki BW, Piekarz AD, Jackson JO II, Cummins TR. 2010. Human voltage-gated sodium channel mutations that cause inherited neuronal and muscle channelopathies increase resurgent sodium currents. J Clin Invest 120: 369-378.

Jensen HS, Grunnet M, Bastlund JF. 2014. Therapeutic potential of $\mathrm{Na}_{\mathrm{V}} 1.1$ activators. Trends Pharmacol Sci 35: $113-118$.

Jiao J, Yang Y, Shi Y, Chen J, Gao R, Fan Y, Yao H, Liao W, Sun XF, Gao S. 2013. Modeling Dravet syndrome using induced pluripotent stem cells (iPSCs) and directly converted neurons. Hum Mol Genet 22: 4241-4252.

Kaplan MR, Cho MH, Ullian EM, Isom LL, Levinson SR, Barres BA. 2001. Differential control of clustering of the sodium channels $\mathrm{Na}_{\mathrm{v}} 1.2$ and $\mathrm{Na}_{\mathrm{v}} 1.6$ at developing CNS nodes of Ranvier. Neuron 30: 105-119.

Kearney JA, Plummer NW, Smith MR, Kapur J, Cummins TR, Waxman SG, Goldin AL, Meisler MH. 2001. A gainof-function mutation in the sodium channel gene $\operatorname{Scn} 2 \mathrm{a}$ results in seizures and behavioral abnormalities. Neuroscience 102: 307-317.

Kellenberger S, West JW, Scheuer T, Catterall WA. 1997. Molecular analysis of the putative inactivation particle in the inactivation gate of brain type IIA $\mathrm{Na}^{+}$channels. J Gen Physiol 109: 589-605. 
Keller BU, Hartshorne RP, Talvenheimo JA, Catterall WA Montal M. 1986. Sodium channels in planar lipid bilayers. Channel gating kinetics of purified sodium channels modified by batrachotoxin. J Gen Physiol 88: 1-23.

Klassen T, Davis C, Goldman A, Burgess D, Chen T, Wheeler D, McPherson J, Bourquin T, Lewis L, Villasana D, et al. 2011. Exome sequencing of ion channel genes reveals complex profiles confounding personal risk assessment in epilepsy. Cell 145: 1036-1048.

Kole MH, Ilschner SU, Kampa BM, Williams SR, Ruben PC, Stuart GJ. 2008. Action potential generation requires a high sodium channel density in the axon initial segment. Nat Neurosci 11: 178-186.

Kuo CC, Bean BP. 1994. Slow binding of phenytoin to inactivated sodium channels in rat hippocampal neurons. Mol Pharmacol 46: 716-725.

Lancaster MA, Renner M, Martin CA, Wenzel D, Bicknell LS, Hurles ME, Homfray T, Penninger JM, Jackson AP, Knoblich JA. 2013. Cerebral organoids model human brain development and microcephaly. Nature 501: 373-379.

Larsen J, Carvill GL, Gardella E, Kluger G, Schmiedel G, Barisic N, Depienne C, Brilstra E, Mang Y, Nielsen JE, et al. 2015. The phenotypic spectrum of SCN8A encephalopathy. Neurology 84: 480-489.

Lauxmann S, Boutry-Kryza N, Rivier C, Mueller S, Hedrich UB, Maljevic S, Szepetowski P, Lerche H, Lesca G. 2013. An SCN2A mutation in a family with infantile seizures from Madagascar reveals an increased subthreshold $\mathrm{Na}^{+}$ current. Epilepsia 54: e117-e121.

Liao Y, Anttonen AK, Liukkonen E, Gaily E, Maljevic S, Schubert S, Bellan-Koch A, Petrou S, Ahonen VE, Lerche $\mathrm{H}$, et al. 2010. SCN2A mutation associated with neonatal epilepsy, late-onset episodic ataxia, myoclonus, and pain. Neurology 75: 1454-1458.

Liu Y, Lopez-Santiago LF, Yuan Y, Jones JM, Zhang H, O’Malley HA, Patino GA, O’Brien JE, Rusconi R, Gupta A, et al. 2013. Dravet syndrome patient-derived neurons suggest a novel epilepsy mechanism. Ann Neurol 74: 128 139.

Lorincz A, Nusser Z. 2010. Molecular identity of dendritic voltage-gated sodium channels. Science 328: 906-909.

Lossin C, Wang DW, Rhodes TH, Vanoye CG, George AL Jr. 2002. Molecular basis of an inherited epilepsy. Neuron 34: $877-884$.

Lossin C, Rhodes TH, Desai RR, Vanoye CG, Wang D, Carniciu S, Devinsky O, George AL Jr. 2003. Epilepsy-associated dysfunction in the voltage-gated neuronal sodium channel SCN1A. J Neurosci 23: 11289-11295.

Lytton WW. 2008. Computer modelling of epilepsy. Nat Rev Neurosci 9: 626-637.

Magee JC, Johnston D. 1995. Synaptic activation of voltagegated channels in the dendrites of hippocampal pyramidal neurons. Science 268: 301-304.

Marini C, Scheffer IE, Nabbout R, Suls A, De Jonghe P, Zara F, Guerrini R. 2011. The genetics of Dravet syndrome. Epilepsia 52: 24-29.

Marionneau C, Carrasquillo Y, Norris AJ, Townsend RR, Isom LL, Link AJ, Nerbonne JM. 2012. The sodium channel accessory subunit $\mathrm{Na}_{\mathrm{v}} \beta 1$ regulates neuronal excitabil- ity through modulation of repolarizing voltage-gated $\mathrm{K}^{+}$ channels. J Neurosci 32: 5716-5727.

Martin MS, Tang B, Papale LA, Yu FH, Catterall WA, Escayg A. 2007. The voltage-gated sodium channel Scn8a is a genetic modifier of severe myoclonic epilepsy of infancy. Hum Mol Genet 16: 2892-2899.

Martin MS, Dutt K, Papale LA, Dube CM, Dutton SB, de Haan G, Shankar A, Tufik S, Meisler MH, Baram TZ, et al. 2010. Altered function of the SCN1A voltage-gated sodium channel leads to $\gamma$-aminobutyric acid-ergic (GABAergic) interneuron abnormalities. J Biol Chem 285: 9823-9834.

McCormick KA, Isom LL, Ragsdale D, Smith D, Scheuer T, Catterall WA. 1998. Molecular determinants of $\mathrm{Na}^{+}$ channel function in the extracellular domain of the $\beta 1$ subunit. J Biol Chem 273: 3954-3962.

McLean MJ, Macdonald RL. 1986. Carbamazepine and 10,11-epoxycarbamazepine produce use- and voltagedependent limitation of rapidly firing action potentials of mouse central neurons in cell culture. J Pharmacol Exp Ther 238: 727-738.

McNamara JO. 1994. Cellular and molecular basis of epilepsy. J Neurosci 14: 3413-3425.

McPhee JC, Ragsdale DS, Scheuer T, Catterall WA. 1998. A critical role for the S4-S5 intracellular loop in domain IV of the sodium channel $\alpha$-subunit in fast inactivation. J Biol Chem 273: 1121-1129.

Meadows LS, Malhotra J, Loukas A, Thyagarajan V, KazenGillespie KA, Koopman MC, Kriegler S, Isom LL, Ragsdale DS. 2002. Functional and biochemical analysis of a sodium channel $\beta 1$ subunit mutation responsible for generalized epilepsy with febrile seizures plus type 1. J Neurosci 22: 10699-10709.

Mulley JC, Scheffer IE, Petrou S, Dibbens LM, Berkovic SF Harkin LA. 2005. SCN1A mutations and epilepsy. Hum Mutat 25: 535-542.

Nguyen HM, Miyazaki H, Hoshi N, Smith BJ, Nukina N, Goldin AL, Chandy KG. 2012. Modulation of voltagegated $\mathrm{K}^{+}$channels by the sodium channel $\beta 1$ subunit. Proc Nat Acad Sci 109: 18577-18582.

O'Brien JE, Meisler MH. 2013. Sodium channel SCN8A $\left(\mathrm{Na}_{\mathrm{V}}\right.$ 1.6): Properties and de novo mutations in epileptic encephalopathy and intellectual disability. Front Genet 4: 213 .

Ogiwara I, Miyamoto H, Morita N, Atapour N, Mazaki E, Inoue I, Takeuchi T, Itohara S, Yanagawa Y, Obata K, et al. 2007. $\mathrm{Na}_{\mathrm{v}} 1.1$ localizes to axons of parvalbumin-positive inhibitory interneurons: A circuit basis for epileptic seizures in mice carrying an Scnla gene mutation. J Neurosci 27: 5903-5914.

Ogiwara I, Ito K, Sawaishi Y, Osaka H, Mazaki E, Inoue I, Montal M, Hashikawa T, Shike T, Fujiwara T, et al. 2009. De novo mutations of voltage-gated sodium channel $\alpha$ II gene SCN2A in intractable epilepsies. Neurology 73: 1046-1053.

Ogiwara I, Nakayama T, Yamagata T, Ohtani H, Mazaki E, Tsuchiya S, Inoue Y, Yamakawa K. 2012. A homozygous mutation of voltage-gated sodium channel $\beta_{\text {I }}$ gene SCN1B in a patient with Dravet syndrome. Epilepsia 53: e200-e203.

Oliva MK, McGarr TC, Beyer BJ, Gazina E, Kaplan DI, Cordeiro L, Thomas E, Dib-Hajj SD, Waxman SG, Frankel 
D.I. Kaplan et al.

WN, et al. 2014. Physiological and genetic analysis of multiple sodium channel variants in a model of genetic absence epilepsy. Neurobiol Dis 67: 180-190.

Palmer LM, Stuart GJ. 2006. Site of action potential initiation in layer 5 pyramidal neurons. J Neurosci 26: 1854 1863.

Papale LA, Beyer B, Jones JM, Sharkey LM, Tufik S, Epstein M, Letts VA, Meisler MH, Frankel WN, Escayg A. 2009. Heterozygous mutations of the voltage-gated sodium channel SCN8A are associated with spike-wave discharges and absence epilepsy in mice. Hum Mol Genet 18: 1633-1641.

Patino GA, Claes LR, Lopez-Santiago LF, Slat EA, Dondeti RS, Chen C, O'Malley HA, Gray CB, Miyazaki H, Nukina $\mathrm{N}$, et al. 2009. A functional null mutation of SCN1B in a patient with Dravet syndrome. J Neurosci 29: 1076410778 .

Patino GA, Brackenbury WJ, Bao Y, Lopez-Santiago LF, O'Malley HA, Chen C, Calhoun JD, Lafreniere RG, Cossette P, Rouleau GA, et al. 2011. Voltage-gated $\mathrm{Na}^{+}$channel $\beta 1 \mathrm{~B}$ : A secreted cell adhesion molecule involved in human epilepsy. J Neurosci 31: 14577-14591.

Patton DE, West JW, Catterall WA, Goldin AL. 1992. Amino acid residues required for fast $\mathrm{Na}^{+}$-channel inactivation: Charge neutralizations and deletions in the III-IV linker. Proc Natl Acad Sci 89: 10905-10909.

Patton DE, Isom LL, Catterall WA, Goldin AL. 1994. The adult rat brain $\beta 1$ subunit modifies activation and inactivation gating of multiple sodium channel $\alpha$ subunits. J Biol Chem 269: 17649-17655.

Payandeh J, Scheuer T, Zheng N, Catterall WA. 2011. The crystal structure of a voltage-gated sodium channel. $\mathrm{Na}$ ture 475: 353-358.

Ragsdale DS, Scheuer T, Catterall WA. 1991. Frequency and voltage-dependent inhibition of type IIA $\mathrm{Na}^{+}$channels, expressed in a mammalian cell line, by local anesthetic, antiarrhythmic, and anticonvulsant drugs. Mol Pharmacol 40: 756-765.

Raman IM, Bean BP. 1997. Resurgent sodium current and action potential formation in dissociated cerebellar Purkinje neurons. J Neurosci 17: 4517-4526.

Santhakumar V, Aradi I, Soltesz I. 2005. Role of mossy fiber sprouting and mossy cell loss in hyperexcitability: A network model of the dentate gyrus incorporating cell types and axonal topography. J Neurophysiol 93: 437-453.

Sawyer NT, Papale LA, Eliason J, Neigh GN, Escayg A. 2014. Scn8a voltage-gated sodium channel mutation alters seizure and anxiety responses to acute stress. Psychoneuroendocrinology 39: 225-236.

Scheffer IE, Harkin LA, Grinton BE, Dibbens LM, Turner SJ, Zielinski MA, Xu R, Jackson G, Adams J, Connellan M, et al. 2007. Temporal lobe epilepsy and $\mathrm{GEFS}^{+}$phenotypes associated with $S C N 1 B$ mutations. Brain 130: 100-109.

Schutte RJ, Schutte SS, Algara J, Barragan EV, Gilligan J, Staber C, Savva YA, Smith MA, Reenan R, O'Dowd DK. 2014. Knock-in model of Dravet syndrome reveals a constitutive and conditional reduction in sodium current. $J$ Neurophysiol 112: 903-912.

Shi X, Yasumoto S, Nakagawa E, Fukasawa T, Uchiya S, Hirose S. 2009. Missense mutation of the sodium channel gene SCN2A causes Dravet syndrome. Brain Dev 31: $758-762$.
Smith MR, Goldin AL. 1997. Interaction between the sodium channel inactivation linker and domain III S4-S5. Biophys J 73: 1885-1895.

Snead OC III, Hosey LC. 1985. Exacerbation of seizures in children by carbamazepine. N Engl J Med 313: 916-921.

Sokolov S, Scheuer T, Catterall WA. 2005. Ion permeation through a voltage-sensitive gating pore in brain sodium channels having voltage sensor mutations. Neuron 47: 183-189.

Sokolov S, Scheuer T, Catterall WA. 2007. Gating pore current in an inherited ion channelopathy. Nature 446: $76-$ 78 .

Song JH, Huang CS, Nagata K, Yeh JZ, Narahashi T. 1997. Differential action of riluzole on tetrodotoxin-sensitive and tetrodotoxin-resistant sodium channels. J Pharmacol Exp Ther 282: 707-714.

Spampanato J, Escayg A, Meisler MH, Goldin AL. 2001. Functional effects of two voltage-gated sodium channel mutations that cause generalized epilepsy with febrile seizures plus type 2. J Neurosci 21: 7481-7490.

Spampanato J, Escayg A, Meisler MH, Goldin AL. 2003. Generalized epilepsy with febrile seizures plus type $2 \mathrm{mu}$ tation W1204R alters voltage-dependent gating of $\mathrm{Na}_{\mathrm{v}} 1.1$ sodium channels. Neuroscience 116: 37-48.

Spampanato J, Aradi I, Soltesz I, Goldin AL. 2004a. Increased neuronal firing in computer simulations of sodium channel mutations that cause generalized epilepsy with febrile seizures plus. J Neurophysiol 91: 2040-2050.

Spampanato J, Kearney JA, de Haan G, McEwen DP, Escayg A, Aradi I, MacDonald BT, Levin SI, Soltesz I, Benna P, et al. 2004b. A novel epilepsy mutation in the sodium channel SCN1A identifies a cytoplasmic domain for $\beta$ subunit interaction. J Neurosci 24: 10022-10034.

Striano P, Bordo L, Lispi ML, Specchio N, Minetti C, Vigevano F, Zara F. 2006. A novel SCN2A mutation in family with benign familial infantile seizures. Epilepsia 47: $218-220$.

Stuart G, Schiller J, Sakmann B. 1997a. Action potential initiation and propagation in rat neocortical pyramidal neurons. J Physiol 505: 617-632.

Stuart G, Spruston N, Sakmann B, Hausser M. 1997b. Action potential initiation and backpropagation in neurons of the mammalian CNS. Trends Neurosci 20: 125-131.

Sun L, Gilligan J, Staber C, Schutte RJ, Nguyen V, O’Dowd DK, Reenan R. 2012. A knock-in model of human epilepsy in Drosophila reveals a novel cellular mechanism associated with heat-induced seizure. J Neurosci 32: 14145-14155.

Tammaro P, Conti F, Moran O. 2002. Modulation of sodium current in mammalian cells by an epilepsy-correlated $\beta 1$ subunit mutation. Biochem Biophys Res Commun 291: $1095-1101$.

Theile JW, Cummins TR. 2011. Inhibition of $\mathrm{Na}_{\mathrm{v}} \beta 4$ peptide-mediated resurgent sodium currents in $\mathrm{Na}_{\mathrm{v}} 1.7$ channels by carbamazepine, riluzole, and anandamide. $\mathrm{Mol}$ Pharmacol 80: 724-734.

Thomas EA, Petrou S. 2013. Network-specific mechanisms may explain the paradoxical effects of carbamazepine and phenytoin. Epilepsia 54: 1195-1202.

Thomas EA, Reid CA, Berkovic SF, Petrou S. 2009. Prediction by modeling that epilepsy may be caused by very 
small functional changes in ion channels. Arch Neurol 66: $1225-1232$.

Van Wart A, Trimmer JS, Matthews G. 2007. Polarized distribution of ion channels within microdomains of the axon initial segment. J Comp Neurol 500: 339-352.

Veeramah KR, O’Brien JE, Meisler MH, Cheng X, Dib-Hajj SD, Waxman SG, Talwar D, Girirajan S, Eichler EE, Restifo LL, et al. 2012. De novo pathogenic SCN8A mutation identified by whole-genome sequencing of a family quartet affected by infantile epileptic encephalopathy and SUDEP. Am J Hum Genet 90: 502-510.

Wagnon JL, Korn MJ, Parent R, Tarpey TA, Jones JM, Hammer MF, Murphy GG, Parent JM, Meisler MH. 2015. Convulsive seizures and SUDEP in a mouse model of SCN8A epileptic encephalopathy. Hum Mol Genet 24: 506-515.

Wallace RH, Wang DW, Singh R, Scheffer IE, George AL Jr Phillips HA, Saar K, Reis A, Johnson EW, Sutherland GR, et al. 1998. Febrile seizures and generalized epilepsy associated with a mutation in the $\mathrm{Na}^{+}$-channel $\beta 1$ subunit gene SCN1B. Nat Genet 19: 366-370.

Wallace RH, Scheffer IE, Parasivam G, Barnett S, Wallace GB, Sutherland GR, Berkovic SF, Mulley JC. 2002. Generalized epilepsy with febrile seizures plus: Mutation of the sodium channel subunit SCN1B. Neurology 58: 1426-1429.

Wang SJ, Wang KY, Wang WC. 2004. Mechanisms underlying the riluzole inhibition of glutamate release from rat cerebral cortex nerve terminals (synaptosomes). Neuroscience 125: 191-201.

Wang Y, Brittain JM, Jarecki BW, Park KD, Wilson SM, Wang B, Hale R, Meroueh SO, Cummins TR, Khanna R. 2010. In silico docking and electrophysiological characterization of lacosamide binding sites on collapsin response mediator protein-2 identifies a pocket important in modulating sodium channel slow inactivation. J Biol Chem 285: 25296-25307.

West JW, Patton DE, Scheuer T, Wang Y, Goldin AL, Catterall WA. 1992. A cluster of hydrophobic amino acid residues required for fast $\mathrm{Na}^{+}$-channel inactivation. Proc Natl Acad Sci 89: 10910-10914.

Wimmer VC, Reid CA, Mitchell S, Richards KL, Scaf BB, Leaw BT, Hill EL, Royeck M, Horstmann MT, Cromer BA, et al. 2010. Axon initial segment dysfunction in a mouse model of genetic epilepsy with febrile seizures plus. JClin Invest 120: 2661-2671.

Wolff C, Carrington B, Varrin-Doyer M, Vandendriessche A, Van der Perren C, Famelart M, Gillard M, Foerch P, Rogemond V, Honnorat J, et al. 2012. Drug binding assays do not reveal specific binding of lacosamide to collapsin response mediator protein 2 (CRMP-2). $\mathrm{CNS} \mathrm{Neu-}$ rosci Ther 18: 493-500.

Xu R, Thomas EA, Gazina EV, Richards KL, Quick M, Wallace RH, Harkin LA, Heron SE, Berkovic SF, Scheffer IE, et al. 2007a. Generalized epilepsy with febrile seizures plus-associated sodium channel $\beta 1$ subunit mutations severely reduce $\beta$ subunit-mediated modulation of sodium channel function. Neuroscience 148: 164-174.

Xu R, Thomas EA, Jenkins M, Gazina EV, Chiu C, Heron SE, Mulley JC, Scheffer IE, Berkovic SF, Petrou S. 2007b. A childhood epilepsy mutation reveals a role for developmentally regulated splicing of a sodium channel. Mol Cell Neurosci 35: 292-301.

Yang YC, Kuo CC. 2002. Inhibition of $\mathrm{Na}^{+}$current by imipramine and related compounds: Different binding kinetics as an inactivation stabilizer and as an open channel blocker. Mol Pharmacol 62: 1228-1237.

Yu FH, Westenbroek RE, Silos-Santiago I, McCormick KA, Lawson D, Ge P, Ferriera H, Lilly J, DiStefano PS, Catterall WA, et al. 2003. Sodium channel $\beta 4$, a new disulfidelinked auxiliary subunit with similarity to $\beta 2$. J Neurosci 23: 7577-7585.

Yu FH, Mantegazza M, Westenbroek RE, Robbins CA, Kalume F, Burton KA, Spain WJ, McKnight GS, Scheuer T, Catterall WA. 2006. Reduced sodium current in GABAergic interneurons in a mouse model of severe myoclonic epilepsy in infancy. Nat Neurosci 9: 1142-1149. 


\section{$\&_{\mathrm{CSH}}^{\infty} \&$ Cold Spring Harbor

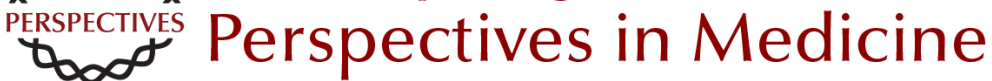

\section{Role of Sodium Channels in Epilepsy}

David I. Kaplan, Lori L. Isom and Steven Petrou

Cold Spring Harb Perspect Med 2016; doi: 10.1101/cshperspect.a022814 originally published online May 3, 2016

\section{Subject Collection Epilepsy: The Biology of a Spectrum Disorder}

The Epilepsy Spectrum: Targeting Future Research Challenges

Gregory L. Holmes and Jeffrey L. Noebels

Role of Sodium Channels in Epilepsy

David I. Kaplan, Lori L. Isom and Steven Petrou

\section{Mechanisms of Action of Antiseizure Drugs and the Ketogenic Diet \\ Michael A. Rogawski, Wolfgang Löscher and Jong M. Rho}

Epilepsy and Autism

Ashura W. Buckley and Gregory L. Holmes

Immunity and Inflammation in Epilepsy

Annamaria Vezzani, Bethan Lang and Eleonora Aronica

Hyperpolarization-Activated Cyclic

Nucleotide-Gated (HCN) Channels in Epilepsy Gary P. Brennan, Tallie Z. Baram and Nicholas P. Poolos

The Role of Calcium Channels in Epilepsy Sanjeev Rajakulendran and Michael G. Hanna

Interneuron Transplantation as a Treatment for Epilepsy

Robert F. Hunt and Scott C. Baraban
Common Mechanisms Underlying

Epileptogenesis and the Comorbidities of

Epilepsy

Andrey Mazarati and Raman Sankar

The Diathesis-Epilepsy Model: How Past Events Impact the Development of Epilepsy and

Comorbidities

Christophe Bernard

Potassium Channels in Epilepsy

Rüdiger Köhling and Jakob Wolfart

GABAergic Synchronization in Epilepsy Roustem Khazipov

Status Epilepticus

Syndi Seinfeld, Howard P. Goodkin and Shlomo Shinnar

Neonatal and Infantile Epilepsy: Acquired and

Genetic Models Aristea S. Galanopoulou and Solomon L. Moshé

Epigenetics and Epilepsy

David C. Henshall and Katja Kobow

Microcircuits in Epilepsy: Heterogeneity and Hub Cells in Network Synchronization

Anh Bui, Hannah K. Kim, Mattia Maroso, et al.

For additional articles in this collection, see http://perspectivesinmedicine.cshlp.org/cgi/collection/ 